\title{
Correlation between fracture surface morphology and toughness in Zr-based bulk metallic glasses
}

\author{
Jin-Yoo Suh \\ W.M. Keck Laboratory of Engineering Materials, California Institute of Technology, Pasadena, \\ California 91125; and Korea Institute of Science \& Technology, Seoul 136-791, Republic of Korea \\ R. Dale Conner ${ }^{\text {a) }}$ \\ California State University Northridge, Northridge, California 91330 \\ C. Paul Kim \\ W.M. Keck Laboratory of Engineering Materials, California Institute of Technology, Pasadena, \\ California 91125; and Liquidmetal Technologies, Rancho Santa Margarita, California 92688
}

Marios D. Demetriou and William L. Johnson

W.M. Keck Laboratory of Engineering Materials, California Institute of Technology, Pasadena, California 91125

(Received 30 September 2009; accepted 14 January 2010)

\begin{abstract}
Fracture surfaces of Zr-based bulk metallic glasses of various compositions tested in the as-cast and annealed conditions were analyzed using scanning electron microscopy. The tougher samples have shown highly jagged patterns at the beginning stage of crack propagation, and the length and roughness of this jagged pattern correlate well with the measured fracture toughness values. These jagged patterns, the main source of energy dissipation in the sample, are attributed to the formation of shear bands inside the sample. This observation provides strong evidence of significant "plastic zone" screening at the crack tip.
\end{abstract}

\section{INTRODUCTION}

Bulk metallic glasses (BMGs) fail without detectable plasticity when loaded in the absence of geometrical confinement, as, for example, in tension or in bending of plates with thicknesses greater than the material characteristic length scale. ${ }^{1,2}$ For fracture toughness measurements, typical test geometries are compact tension (CT) and single-edge notched bending (SENB). The loading geometry of both methods is bending of plates that are several millimeters thick. Considering that typical characteristic process zone sizes for BMGs are below $1 \mathrm{~mm},{ }^{3}$ one would expect BMG to exhibit poor toughness. However, fracture toughness data for Vitreloy $1\left(\mathrm{Zr}_{41.2} \mathrm{Ti}_{13.8}\right.$ $\left.\mathrm{Cu}_{12.5} \mathrm{Ni}_{10} \mathrm{Be}_{22.5}\right),{ }^{4}$ the first commercial BMG alloy, taken from several reports suggest a range of fracture toughness that extends to values comparable to those of conventional crystalline metals, although the scatter associated with these data is significant. Specifically, the reported fracture toughness of Vitreloy 1 varies between 16 and $55 \mathrm{MPa} \cdot \mathrm{m}^{1 / 2} \cdot{ }^{5-9} \mathrm{In}$ an additional study however in which single-edge notched tension (SENT) was used, the fracture toughness of Vitreloy 1 was reported to be in excess of $130 \mathrm{MPa} \cdot \mathrm{m}^{1 / 2} \cdot{ }^{10}$ Such an extremely high

\footnotetext{
a) Address all correspondence to this author.

e-mail: rdconner@csun.edu
}

DOI: 10.1557/JMR.2010.0112 toughness is surprising, given that the tension loading geometry of SENT is geometrically less confined than the bending loading geometry of CT and SENB. The unusual combination of zero ductility but high fracture toughness of BMGs was also pointed out by Ashby and Greer. ${ }^{3}$ The perceived high fracture toughness of metallic glasses has been attributed to the formation of a high density of shear bands at the crack tip. ${ }^{11}$ However, this argument has only been supported by finite element analysis $^{12}$ and observation of shear band networks that evolved on the outer surfaces of specimens, ${ }^{5,10}$ although it is known that such surface shear bands only reflect the stress state of the free surface dominated by the plane stress condition.

In this study, the fracture surfaces of as-cast and annealed $\mathrm{Zr}$-based BMGs of various compositions were carefully investigated to gain insight on how shear bands form in the regions of plane strain (far from the surface) and whether the extent of shear band propagation correlates to the measured fracture toughness. Various fracture samples from the Vitreloy alloy family were used in this study, including Vitreloy $1\left(\mathrm{Zr}_{41.2} \mathrm{Ti}_{13.8} \mathrm{Cu}_{12.5} \mathrm{Ni}_{10}\right.$ $\left.\mathrm{Be}_{22.5}\right)$, Vitreloy $4\left(\mathrm{Zr}_{46.75} \mathrm{Ti}_{8.25} \mathrm{Cu}_{7.5} \mathrm{Ni}_{10} \mathrm{Be}_{27.5}\right)$, two different four-component variants $\left(\mathrm{Zr}_{33.5} \mathrm{Ti}_{24} \mathrm{Cu}_{15} \mathrm{Be}_{27.5}\right.$ and $\left.\mathrm{Zr}_{44} \mathrm{Ti}_{11} \mathrm{Cu}_{20} \mathrm{Be}_{25}\right)$, and a six-component variant $\left(\mathrm{Zr}_{44}\right.$ $\mathrm{Ti}_{11} \mathrm{Cu}_{9.3} \mathrm{Ni}_{10.2} \mathrm{Be}_{25} \mathrm{Fe}_{0.5}$ ). Samples of $\mathrm{Zr}_{44} \mathrm{Ti}_{11} \mathrm{Cu}_{20} \mathrm{Be}_{25}$ were annealed at three different temperatures prior to 
testing. This wide variation in the chemical and thermodynamic state of the material produced a set of fracture toughness data $\left(K_{\mathrm{Q}}\right)$ that ranged from 6 to $96.8 \mathrm{MPa} \cdot \mathrm{m}^{1 / 2}$. The effect of composition on fracture toughness is discussed in a separate report, ${ }^{13}$ while the effect of annealing will be discussed elsewhere. The present study focuses on fracture surface morphology in an aim to explore the relationship between shear band propagation and toughness.

\section{EXPERIMENTAL}

Approximately $10 \mathrm{~g}$ of arc melted BMG of the various compositions was vacuum cast into a $\mathrm{Cu}$ mold of nominal dimensions of $2.5 \times 8 \times 36 \mathrm{~mm}$ that incorporated a $2 \mathrm{~mm}$ protrusion to form a notch. Lapping and polishing were performed to reduce the possible effect of residual stresses originating from the casting process, which resulted in specimen thicknesses of 1.86-2.26 mm. Fatigue precracking and subsequent quasi-static loading for the determination of the critical load $\left(P_{\mathrm{Q}}\right)$ were performed using an MTS servohydraulic load frame equipped with a three-point bend fixture with $31.75 \mathrm{~mm}$ span. The geometry of the SENB specimen and the definitions of several geometrical terms used in this study are shown in Fig. 1(a). By applying a load corresponding to $\Delta K \cong 10 \mathrm{MPa} \cdot \mathrm{m}^{1 / 2}$ and $K_{\min } / K_{\max } \cong 0.2$ (this ratio is out of range recommended by ASTM E $399,-1 \leq K_{\min } / K_{\max } \leq 0.1$ ), a 1.1-2.4 mm long precrack was obtained after 40,000 150,000 cycles. Starting with an initial crack length $a_{0} \cong$ 3.1 to $4.4 \mathrm{~mm}$ (the sum of the notch length and precrack), a quasi-static compressive displacement of $0.3 \mathrm{~mm} / \mathrm{min}$ $\left(K \approx 40 \mathrm{MPa} \cdot \mathrm{m}^{1 / 2} / \mathrm{min}\right)$ was applied and the load response of the precracked sample was measured. Fracture tough-

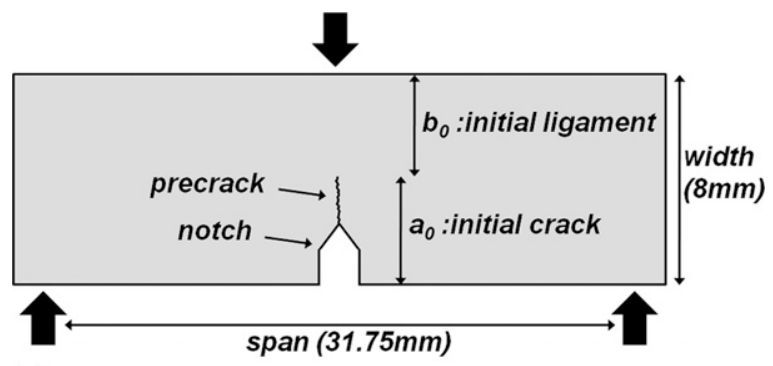

(a)

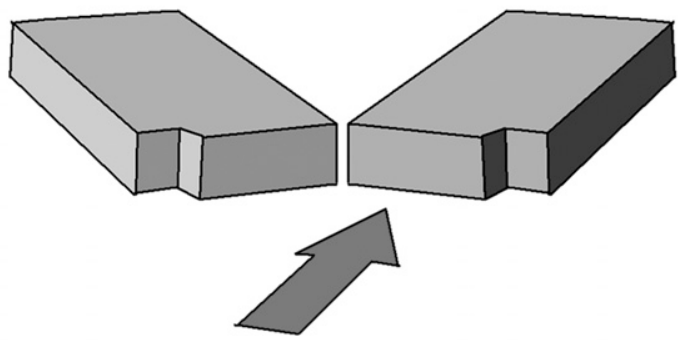

(b)

FIG. 1. (a) Single-edge notched bending fracture specimen geometry and dimension. (b) Viewpoint of fracture surface observation after ultimate fracture. ness $\left(K_{\mathrm{Q}}\right)$ was calculated from the critical load using the formula given in ASTM E 399.A3. It should be clarified that $K_{\mathrm{Q}}$ was used to denote fracture toughness rather than $K_{\text {IC }}$ because the sample thickness did not guarantee plane strain condition in all cases (addressed later in this paper). The compositions and process conditions of the specimens used for this study, along with geometrical information such as specimen thickness and initial crack length $\left(a_{0}\right)$, are listed in Table I. Specimens are numbered in the order of decreasing $K_{\mathrm{Q}}$ in the first column of Table I. These numbers are used to refer to the specific specimens in this report.

\section{RESULTS AND DISCUSSION}

\section{A. Fracture surface of bulk metallic glasses}

Figure 2 shows the fracture surfaces of the various alloys studied. The viewpoint of observation is as described in Fig. 1(b). The images in Fig. 2 are arranged in the order of decreasing fracture toughness. The vertical arrows in all images point to the end of the precrack region. Beginning at the precrack, ultimate fracture occurred by crack propagation from right-to-left under monotonically increasing quasi-static load. The fracture surfaces of some specimens [Figs. 2(a)-2(e)] show highly jagged patterns at the beginning stage of crack propagation [region "A" in Fig. 2(a)], and the length [" $L_{\mathrm{A}}$ " defined in Fig. 2(a), listed in Table I] and degree of roughness of these jagged patterns increases with increasing $K_{\mathrm{Q}}$. This jagged region will be termed as "rough zone" hereafter. As fracture progresses these rough zones (jagged patterns) disappear, and the rest of the fracture surface [region "B" in Fig. 2(a)] shows the typical glassy metal dimple pattern, which is shown in Fig. 3 and reported in many other studies. ${ }^{5-8,14-17}$ The fracture surfaces of low fracture toughness specimens shown in Figs. 2(f) and 2(g) do not exhibit the characteristic rough topography in front of the precrack, and they appear to be uniformly filled with dimples created by mode 1 opening (Fig. 3). The severe embrittlement caused by annealing the specimens for 2.5 days at $50{ }^{\circ} \mathrm{C}$ below the glasstransition temperature $\left(T_{\mathrm{g}}, 340{ }^{\circ} \mathrm{C}\right.$ measured by $20 \mathrm{~K} / \mathrm{min}$ DSC scan ${ }^{13}$ ) resulted in the fracture surface shown in Fig. 2(h). This mirrorlike fracture surface consists of hundred-nanometer sized dimples [Fig. 3(d)], as observed by $\mathrm{Xi}$ et al. ${ }^{14}$

\section{B. Size of the dimple patterns}

Dimple patterns of the BMG fracture surfaces [region "B" in Fig. 2(a)] are shown in Fig. 3. This region of the fracture surface is covered by isotropic dimples (no specific directionality) indicating that failure occurs by pure opening mode (Mode 1). Dimple patterns have been explained to form by massive flow of softened material 
TABLE I. Experimental conditions and data of BMGs used in this study.

\begin{tabular}{|c|c|c|c|c|c|c|c|c|}
\hline $\begin{array}{l}\text { Sample } \\
\text { number }\end{array}$ & Composition & Annealing & $\begin{array}{l}\text { Thickness } \\
(\mathrm{mm})\end{array}$ & $\begin{array}{c}\text { Initial } \\
\text { crack } a_{0}(\mathrm{~mm})\end{array}$ & $\begin{array}{c}K_{\mathrm{Q}} \\
\left(\mathrm{MPa} \cdot \mathrm{m}^{1 / 2}\right)\end{array}$ & $L_{\mathrm{A}}(\mathrm{mm})$ & $\sigma_{\mathrm{y}}(\mathrm{GPa})$ & $\begin{array}{c}\text { Plastic zone } \\
\text { size }(\mu \mathrm{m})\end{array}$ \\
\hline S1 & $\mathrm{Zr}_{33.5} \mathrm{Ti}_{24} \mathrm{Cu}_{15} \mathrm{Be}_{27.5}$ & As cast & 2.16 & 3.1 & 96.8 & 2.33 & 1.75 & 974 \\
\hline S2 & $\mathrm{Zr}_{44} \mathrm{Ti}_{11} \mathrm{Cu}_{20} \mathrm{Be}_{25}$ & As cast & 2.13 & 3.5 & 85.5 & 2.07 & 1.8 & 718 \\
\hline S3 & $\mathrm{Zr}_{44} \mathrm{Ti}_{11} \mathrm{Cu}_{20} \mathrm{Be}_{25}$ & As cast & 2.22 & 4.3 & 83.9 & 1.68 & 1.8 & 692 \\
\hline S4 & $\mathrm{Zr}_{33.5} \mathrm{Ti}_{24} \mathrm{Cu}_{15} \mathrm{Be}_{27.5}$ & As cast & 2.19 & 4.4 & 80.8 & 1.69 & 1.75 & 679 \\
\hline S5 & $\mathrm{Zr}_{41.2} \mathrm{Ti}_{13.8} \mathrm{Ni}_{10} \mathrm{Cu}_{12.5} \mathrm{Be}_{22.5}$ & As cast & 2.18 & 3.8 & 74.4 & 1.95 & 1.86 & 509 \\
\hline S6 & $\mathrm{Zr}_{33.5} \mathrm{Ti}_{24} \mathrm{Cu}_{15} \mathrm{Be}_{27.5}$ & As cast & 2.26 & 3.5 & 69.2 & 1.84 & 1.75 & 498 \\
\hline S7 & $\mathrm{Zr}_{46.75} \mathrm{Ti}_{8.25} \mathrm{Ni}_{10} \mathrm{Cu}_{7.5} \mathrm{Be}_{27.5}$ & As cast & 2.21 & 4.0 & 54.6 & 1.43 & 1.86 & 274 \\
\hline S8 & $\mathrm{Zr}_{44} \mathrm{Ti}_{11} \mathrm{Cu}_{20} \mathrm{Be}_{25}$ & $350^{\circ} \mathrm{C} 2 \mathrm{~h}$ & 2.12 & 3.9 & 51.3 & 1.58 & $\ldots$ & 259 \\
\hline S9 & $\mathrm{Zr}_{41.2} \mathrm{Ti}_{13.8} \mathrm{Ni}_{10} \mathrm{Cu}_{12.5} \mathrm{Be}_{22.5}$ & As cast & 1.86 & 3.2 & 49.6 & 1.59 & 1.86 & 226 \\
\hline S10 & $\mathrm{Zr}_{44} \mathrm{Ti}_{11} \mathrm{Ni}_{10.2} \mathrm{Cu}_{9.3} \mathrm{Be}_{25} \mathrm{Fe}_{0.5}$ & As cast & 2.15 & 3.7 & 27.5 & 0 & 1.86 & 70 \\
\hline S11 & $\mathrm{Zr}_{41.2} \mathrm{Ti}_{13.8} \mathrm{Ni}_{10} \mathrm{Cu}_{12.5} \mathrm{Be}_{22.5}$ & As cast & 2.22 & 4.1 & 27.3 & 0 & 1.86 & 69 \\
\hline S12 & $\mathrm{Zr}_{44} \mathrm{Ti}_{11} \mathrm{Ni}_{10.2} \mathrm{Cu}_{9.3} \mathrm{Be}_{25} \mathrm{Fe}_{0.5}$ & As cast & 2.16 & 3.7 & 26.4 & 0 & 1.86 & 64 \\
\hline S13 & $\mathrm{Zr}_{44} \mathrm{Ti}_{11} \mathrm{Cu}_{20} \mathrm{Be}_{25}$ & $320^{\circ} \mathrm{C} 25 \mathrm{~h}$ & 2.09 & 4.1 & 25 & 0 & $\ldots$ & 61 \\
\hline S14 & $\mathrm{Zr}_{44} \mathrm{Ti}_{11} \mathrm{Ni}_{10.2} \mathrm{Cu}_{9.3} \mathrm{Be}_{25} \mathrm{Fe}_{0.5}$ & As cast & 2.16 & 3.4 & 21.7 & 0 & 1.86 & 43 \\
\hline $\mathrm{S} 15^{\mathrm{a}}$ & $\mathrm{Zr}_{44} \mathrm{Ti}_{11} \mathrm{Cu}_{20} \mathrm{Be}_{25}$ & $290^{\circ} \mathrm{C} 62 \mathrm{~h}$ & 2.13 & 3.6 & $6^{\mathrm{a}}$ & 0 & $\ldots$ & 4 \\
\hline
\end{tabular}

$a_{0}$, initial crack length $\left(a_{0}=\right.$ length of notch + length of fatigue precrack); $L_{\mathrm{A}}$, size of the rough zone as defined in Fig. 2(a). The plastic zone size is calculated from $K_{\mathrm{Q}}{ }^{2} / \pi / \sigma_{\mathrm{y}}{ }^{2}$ [see Eq. (2)].

${ }^{a}$ Although S15 has the same composition as S2 and S3, this specimen shows significant embrittlement as a result of the annealing treatment. S15 was fatigue cracked before the annealing heat treatment at which point the measured $K_{\mathrm{Q}}$ is over $80 \mathrm{MPa} \cdot \mathrm{m}^{1 / 2}$. After the fatigue crack generation, the specimen was annealed and embrittled to the level of $6 \mathrm{MPa} \cdot \mathrm{m}^{1 / 2}$. In this way, the specimen was able to be precracked by using cyclic loading condition of $K_{\max } \cong 12.5 \mathrm{MPa} \cdot \mathrm{m}^{1 / 2}$.

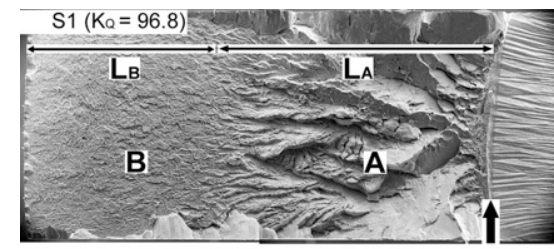

(a)

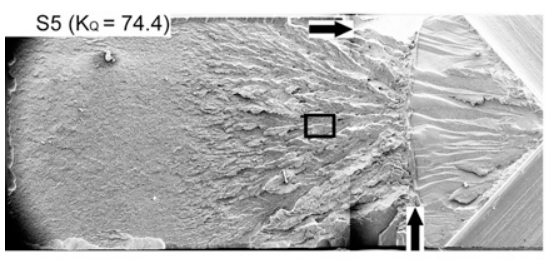

(c)

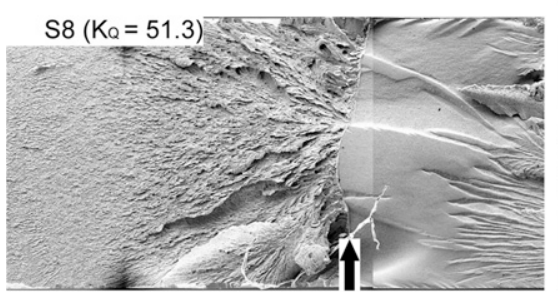

(e)

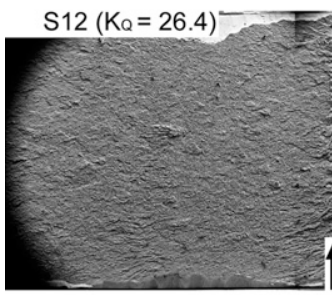

(g)

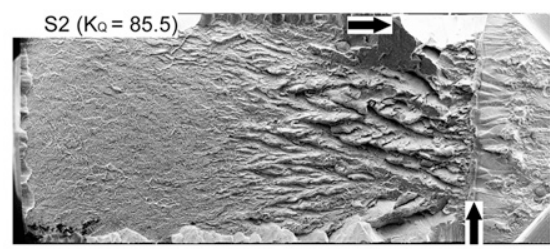

(b)

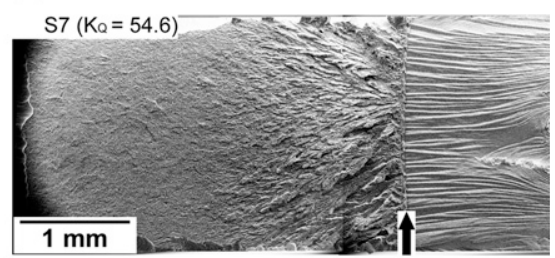

(d)

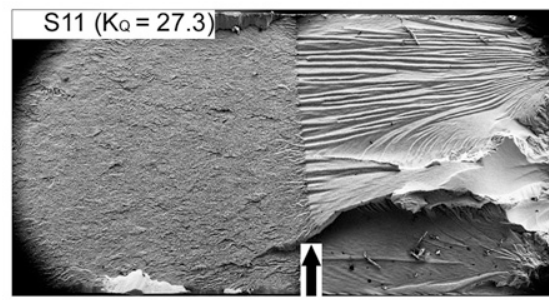

(f)

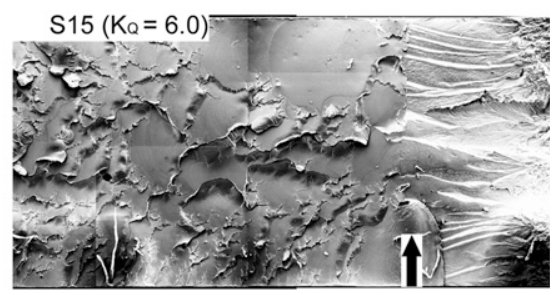

(h)

FIG. 2. Scanning electron micrographs of the fracture surfaces. The vertical arrows mark the location of the initial precracks. Crack propagation is from right to left in each micrograph. (a) Specimen S1, (b) S2, (c) S5, (d) S7, (e) S8, (f) S11, (g) S12, and (h) S15. Measured fracture toughnesses $\left(K_{\mathrm{Q}}\right)$ are shown in the parentheses for all specimens. 


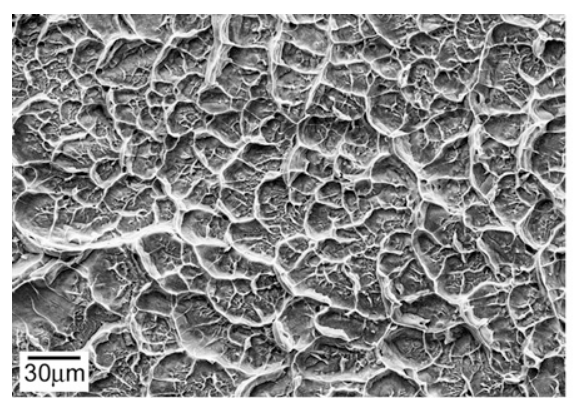

(a)

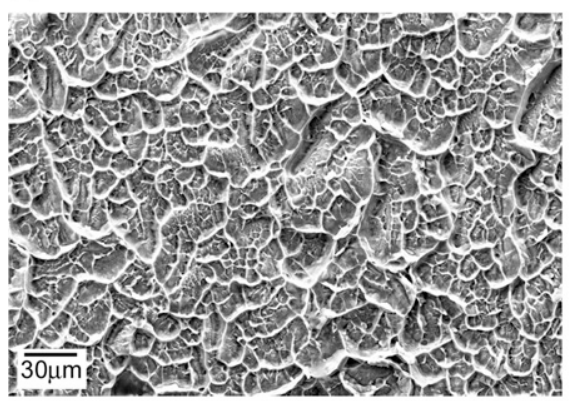

(c)

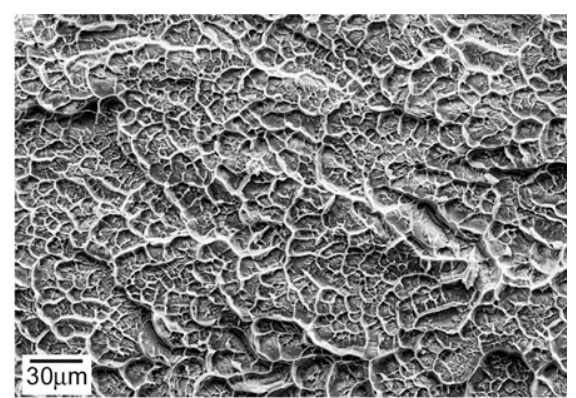

(b)

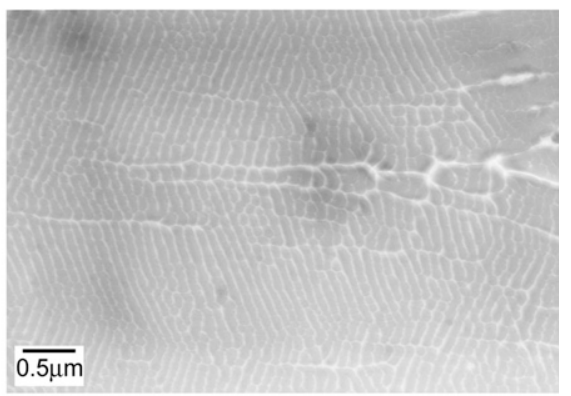

(d)

FIG. 3. Fracture surface of area B [defined in Fig. 2(a)]. (a) Specimen S2, (b) S7, (c) S10, and (d) S15.

at the crack tip ${ }^{18}$ based on Taylor's meniscus instability criterion applied to metallic glass fracture by Argon and Salama ${ }^{19}$ and the correlation between the process zone size and fracture energy recently proposed by $\mathrm{Xi}$ et al. ${ }^{14}$ It is noteworthy that even deeply embrittled BMGs form dimple patterns, which is an indication that they undergo a certain degree of plastic flow prior to fracture [Fig. 3(d)]. The mean area of the dimples in Fig. 3(d) is about $0.03 \mu \mathrm{m}^{2}$. However, the dimple size in Figs. 3(a)-3(c) is not unique, as small dimples reside inside large dimples, and the distinction between these two different dimple sizes is not clear. A distribution of dimple sizes suggests that multiple cavities form, grow, and coalesce leading to plastic flow in front of the crack tip. Based on this observation, both the nucleation of cavities (which might be governed by the critical wave length of the meniscus instability ${ }^{19}$ ) and the stability of the flow in the vicinity of nucleated cavity should be considered important contributing parameters to the fracture behavior. Despite the difficulty in quantifying the size distributions in these figures, it is obvious that the dimple sizes appearing in Fig. 3(a) (the highest $K_{\mathrm{Q}}$ ) are larger than those in Figs. 3(b) and $3(c)$, while the size difference between the dimples in Figs. 3(b) and 3(c) is not significant. Likewise, the quaternary $\mathrm{Zr}_{33.5} \mathrm{Ti}_{24} \mathrm{Cu}_{15} \mathrm{Be}_{27.5}$ (S1, S4 and S6) and $\mathrm{Zr}_{44} \mathrm{Ti}_{11} \mathrm{Cu}_{20} \mathrm{Be}_{25}$ (S2 and S3) alloys listed in Table I, which have $K_{\mathrm{Q}}$ ranging from 69.2 to $96.8 \mathrm{MPa} \cdot \mathrm{m}^{1 / 2}$, consistently have patterns of larger dimple sizes comparable to those shown in Fig. 3(a), while the patterns of $\mathrm{Zr}_{41.2} \mathrm{Ti}_{13.8} \mathrm{Cu}_{12.5} \mathrm{Ni}_{10} \mathrm{Be}_{22.5}$ (Vitreloy 1, S5, S9 and S11),
$\mathrm{Zr}_{46.75} \mathrm{Ti}_{8.25} \mathrm{Cu}_{7.5} \mathrm{Ni}_{10} \mathrm{Be}_{27.5}$ (Vitreloy 4, S7), and $\mathrm{Zr}_{44} \mathrm{Ti}_{11} \mathrm{Cu}_{9.3} \mathrm{Ni}_{10.2} \mathrm{Be}_{25} \mathrm{Fe}_{0.5}$ (S10, S12 and S14) alloys, which have $K_{\mathrm{Q}}$ ranging from 21.7 to $74.4 \mathrm{MPa} \cdot \mathrm{m}^{1 / 2}$, are characterized by the smaller dimple sizes such as those in Figs. 3(b) and 3(c). Since the size of a dimple is a measure of BMG plastic flow prior to failure, a tendency of decreasing dimple size with decreasing fracture toughness is conceivable. Interestingly, BMGs that demonstrate a dimple size distribution similar to those in Figs. 3(b) and 3(c), i.e., Vitreloy 1, Vitreloy 4, and $\mathrm{Zr}_{44} \mathrm{Ti}_{11} \mathrm{Cu}_{9.3} \mathrm{Ni}_{10.2} \mathrm{Be}_{25} \mathrm{Fe}_{0.5}$, exhibit fracture toughness that may be high or low depending on whether a rough zone [the jagged zone in front of the precrack, defined by region "A" in Fig. 2(a)] develops during fracture. Specifically, $K_{\mathrm{Q}}$ for these alloys ranges from 49.6 to $74.4 \mathrm{MPa} \cdot \mathrm{m}^{1 / 2}$ if the fracture surface reveals a rough zone, and from 21.7 to $27.5 \mathrm{MPa} \cdot \mathrm{m}^{1 / 2}$ if no rough zone develops. This behavior suggests that this class of BMGs can be either "tough" or "less tough," and this distinction is characterized by a tendency to develop a jagged rough zone during fracture. Furthermore, it would be reasonable to assume that the mechanical energy spent to generate this jagged rough zone should be significantly more than the energy consumed to generate the dimples.

\section{Stress state around a crack tip (surface)}

On the specimen surface, where the plane stress condition dominates, $\sigma_{z z}=0$. Since $\sigma_{y y}>\sigma_{x x}>\sigma_{z z}=0$, the maximum shear stress component is $\tau_{y z}$ as shown in Fig. 4(a). ${ }^{20}$ The directions of $x, y$, and $z$ axes are defined in 


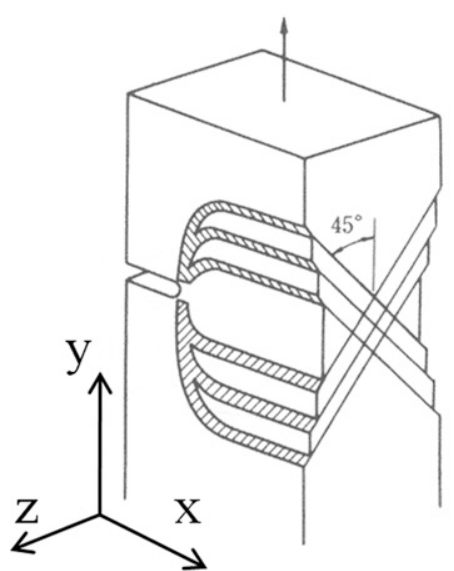

(a)

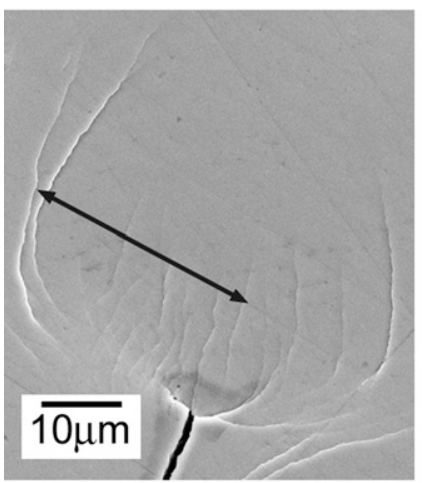

(c)

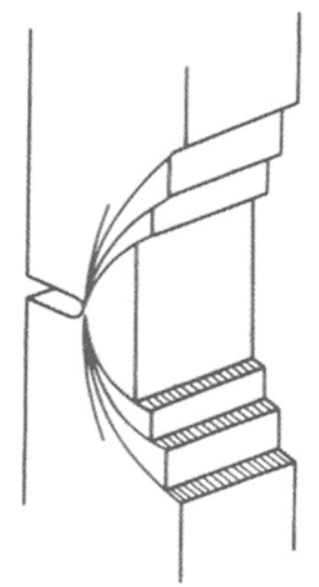

(b)

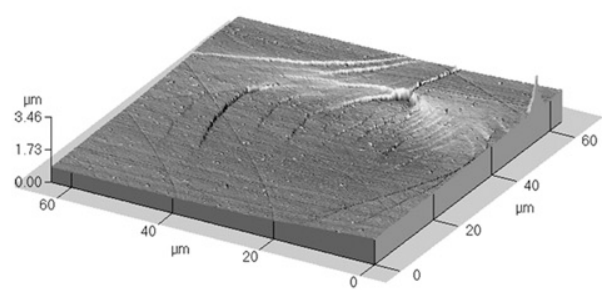

(d)

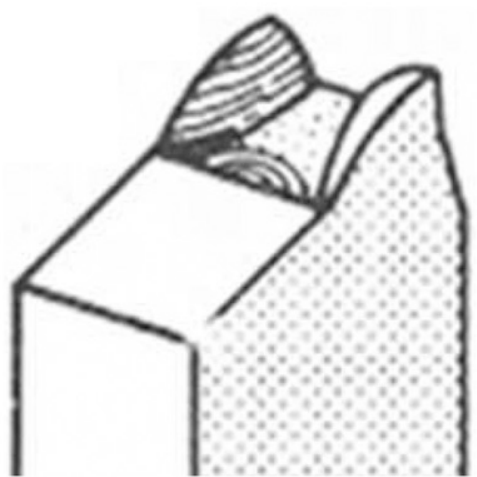

(e)

FIG. 4. Direction of maximum shear stress and resultant slip in front of crack under mode 1 loading $^{20}$ under (a) plane stress condition and (b) plane strain condition. (c) Shape of a surface shear band formed around the crack tip (d) atomic force microscopy (AFM) scan of the area shown in (c). (e) Typical fracture surface of mixed-mode fracture.

Fig. 4(a). Figure 4(c) is a SEM image and Fig. 4(d) is a fast-scanatomic force microscopy (AFM) image of the area surrounding the precrack tip, opened under mode 1 loading, and suggests that the shear offsets are directed into the thickness direction ( $z$-direction). These morphology expectations are depicted in Fig. 4(e), which shows the shear lips, and crescent ahead of the precrack followed by the mountainous topography in the process zone resulting from shear band generation. Shear lips directed into the thickness direction have also been reported by Schneibel et al. ${ }^{21}$ At the initial stage of fracture, cracks at the surface follow one of the shear bands distributed around the crack tip shown in Figs. 4(c) and 4(d). The fracture surfaces near specimen surface are covered with venous patterns, and these patterns look different from the typical dimple patterns shown in Fig. 3. Venous patterns are generally observed from fracture surfaces generated by tensile loading conditions, ${ }^{22-25}$ under which single unstable shear band sliding occurs immediately before fracture. Unlike dimple patterns, which are characterized by isotropic, taller, and thicker walls, vein patterns are characterized by shorter and thinner walls. Presumably, the 
difference in the two patterns can be attributed to a different BMG fluidity at the stage of ultimate fracture. The creation of a veinlike pattern would be associated with a higher fluidity originating from material softening during shear band sliding. A shear band offset of about $4 \mu \mathrm{m}$ can be observed in Fig. 4(d).

\section{Stress state around a crack tip (interior)}

The plane strain condition becomes dominant as the depth from the surface increases. In the plane strain condition, deformation along the $z$-direction [defined in Fig. 4(a)] is confined such that the only shear direction available appears to be $x-y$ direction as shown in Fig. 4(b), and a shear band pattern in front of crack tip forms, as predicted by Tandaiya et al. ${ }^{12}$ The crescent region at the boundary between fatigue precrack and ultimate fracture in the high $K_{\mathrm{Q}}$ samples is evidence of such shear band sliding, as observed in Fig. 5(a), which shows the boundary between fatigue precrack (right to the dotted line) and ultimate fracture (left to the dotted line) for specimen $\mathrm{S} 5\left(K_{\mathrm{Q}}=74.4 \mathrm{MPa} \cdot \mathrm{m}^{1 / 2}\right)$. The dotted line marks the precrack tip boundary before ultimate fracture. The crack growth direction is right to left. On the left of the precrack tip (dotted line), a smooth featureless region is observed (see thick arrow marks), followed by vein patterned region. This surface feature suggests shear band sliding and subsequent fracture. The direction of shear band sliding is indicated by the thick arrows. A possible shear banding mechanism for this fracture behavior was proposed by Tatschl et al. to explain crack tip blunting during loading ${ }^{17}$ [see Fig. 5(d)]. This single shear band mechanism predicts that the distance between points $\alpha$ and $\gamma$ and the distance between points $\beta$ and $\gamma$ [defined in Fig. 5(d)] are different due to the shear band sliding. However, the matching surfaces of the specimen S1 shown in Figs. 5(b) and 5(c) indicate that the distances of matching features (indicated by thin arrows A, B, and C) from the precrack tip are almost the same despite the large amount of shear slip (more than $10 \mu \mathrm{m}$ ) marked by thick arrows. The single shear banding mechanism proposed in Ref. 17 [Fig. 5(d)] therefore is not adequate to explain this behavior. One possible explanation is a combination of multiple shear bands. Flores and Dauskardt observed multiple steps ahead of the precrack [see Fig. 4(b) in Ref. 10], which is also observed in this study.

Beyond this plane strain deformation region, the jagged surfaces [defined by the region "A" in Fig. 2(a)] of the tougher samples shown in Figs. 2(a)-2(e) do not appear to follow the deformation mode discussed previously. The fracture surface shown in Fig. 2(a) has an

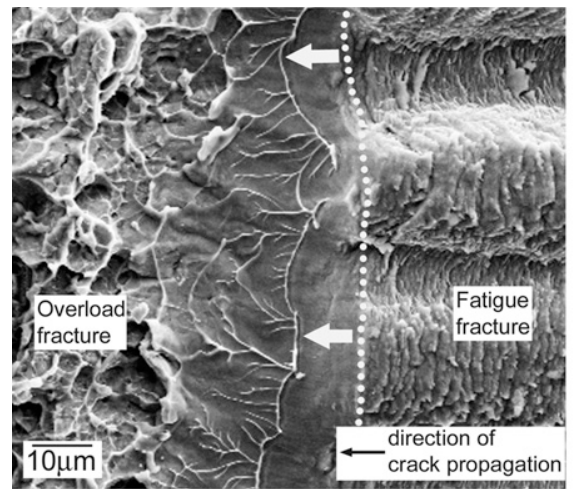

(a)

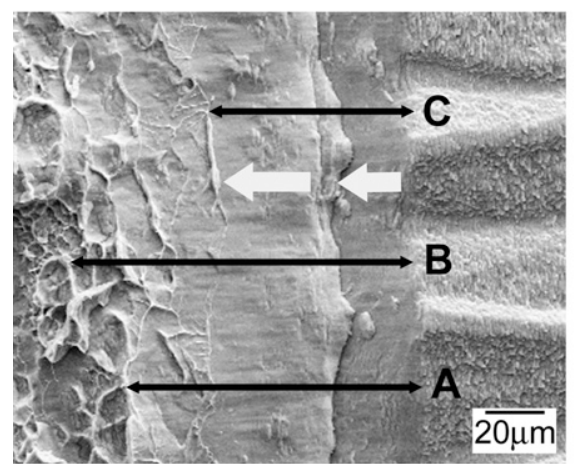

(c)

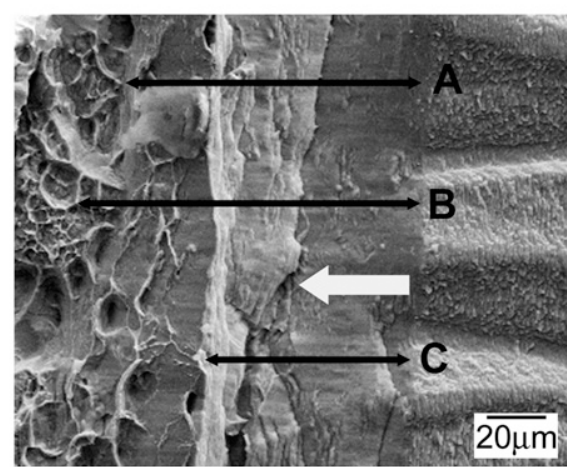

(b)

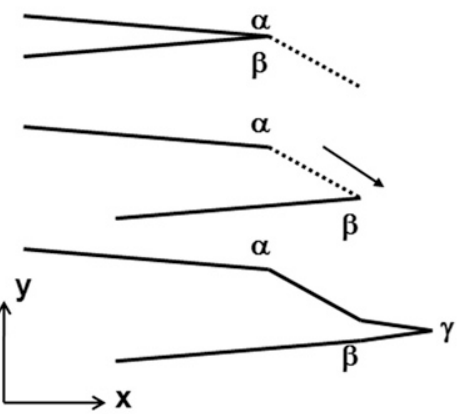

(d)

FIG. 5. (a) Boundary (dotted line) between fatigue precrack (right) and ultimate fracture (left) of specimen S5. Crack growth direction is from right to left. (b, c) Matching surfaces of the boundary of specimen S1. (d) Single shear band mechanism for blunting crack tip. ${ }^{17}$ 
inclination of about $45^{\circ}$ with respect to the mode 1 loading direction, in agreement with Fig. 4(a), and the extensive surface shear banding that reaches almost to the center of the specimen. $K_{\mathrm{Q}}$ for this specimen is $96.8 \mathrm{MPa} \cdot \mathrm{m}^{1 / 2}$; for a valid $K_{\mathrm{IC}}$, the sample would need to be $7.6 \mathrm{~mm}$ thick; thus, the sample is not in plane strain condition. As the samples transition from plane stress through mixed-mode and into the plane strain condition, Figs. 2(b)-2(e), we observe a corresponding change in surface morphology, decreasing in roughness and length. However, careful observation reveals evidence of shear banding even on the less jagged surfaces of Figs. 2(b) 2(e). Figure 6 is a magnified image of the squared area marked in Fig. 2(c). The fracture surface consists of steps running parallel to the crack propagation direction. As previously discussed, venous patterns on the surfaces (indicated by arrows) are observed on fracture surfaces generated by tensile loading. ${ }^{22-25}$ Extensive shear band propagation (sliding) occurs, generating the typical vein pattern. The rest of the fracture surface shown in Fig. 6 resembles the typical dimple pattern of metallic glasses, ${ }^{5-8,14-17}$ generated by direct opening without significant prior shear band sliding.

Although we have plane strain deformation right in front of the crack tip as shown in Fig. $5,^{10,12}$ the evidence of shear banding beyond this region described previously (and shown in Fig. 6) is incongruent with the current understanding of crack tip plasticity ${ }^{10,12}$ in which the crack tip is constrained in the thickness direction. The origin of the shear bands creating the jagged rough zone is not clear yet, but this jagged zone has also been observed in other studies. ${ }^{6,26-28}$ "In some regions, these ridges were quite large and ran nominally parallel to the direction of crack propagation"6 [See their Figs. 8(a) and 15]. Presumably, this shear band pattern shown in Fig. 6 may be caused by the morphology of the fatigue precrack. As shown in Fig. 2, the fracture surface generated by fatigue precracking has ridges running parallel to the crack growth direction.

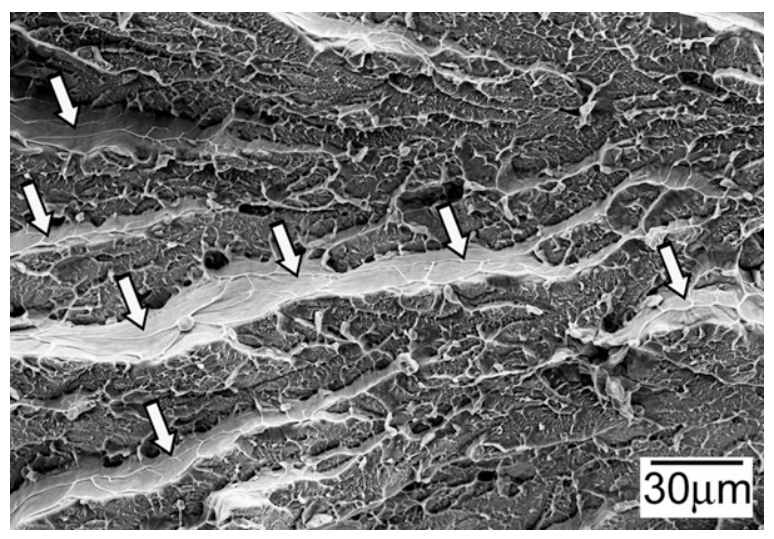

FIG. 6. Magnified image of squared area in Fig. 2(c).
Magnified view of these fatigue fracture surface is given in Figs. 5(a)-5(c) to show that the surfaces have "ridge and furrow" morphology directed normal to the crack front as well as the typical fatigue striations parallel to the crack front. This rough fatigue surface was also observed by Gilbert et al. 6,17,29 Their surface, generated from $\Delta K \approx 10 \mathrm{MPa} \cdot \mathrm{m}^{1 / 2}$ and $\mathrm{d} a / \mathrm{d} N \approx 10^{-8} \mathrm{~m} /$ cycle, agrees with the fatigue precracking condition used in this study. The roughness of the fatigue surfaces progressively diminishes with decreasing growth rates. ${ }^{29}$ However, even at as slow growth rates as with the threshold $\Delta K$ level, the ridges running parallel to the crack growth direction were reported, ${ }^{24,30}$ which indicates that the "ridge and furrow" morphology of the fatigue crack tip may be unavoidable for the BMG fracture mechanics. Irregularity caused by kinks or steps along the crack front might cause a complex stress state in front of the crack and contribute to the jagged morphology. Indeed, $\mathrm{Gao}^{31}$ performed an instability analysis of three-dimensional crack problem that included the shape perturbations parallel to the crack front to explain the ridgelike surface features running parallel to the crack growth direction as shown in Figs. 5(a)-5(c) and Fig. 6. Gao studied the role of T-stress term on determining crack front morphology. The T-stress is known to affect the crack growth direction in two-dimensional crack propagation problem. ${ }^{32}$ Hess and Dauskardt used Gao's T-stress analysis to successfully model the surface morphology of fatigue fracture surface of BMG. ${ }^{30}$ Additional study is required to understand the shear band pattern in the jagged rough zone. It is important to note that the specimens without the rough zone [Figs. 2(f) and 2(g), specimens S10-S15] also have nonplanar ridged fatigue fracture surfaces, which suggests that the nonplanar precrack front might be a necessary, but not a sufficient, condition for the formation of a jagged rough zone.

\section{E. Comment on the validity of $\mathrm{K}_{\mathrm{Q}}$ as plane strain fracture toughness $\left(\mathrm{K}_{\mathrm{IC}}\right)$ based on shear band formation and ASTM size requirement}

A shear band that originates at the surface, where plane stress condition dominates, should be distinguished from one that originates inside the specimen, where plane strain condition prevails. This is because the formation of interior shear bands determines the validity of the measurement as plane strain fracture toughness $\left(K_{\mathrm{IC}}\right)$. Shear bands originating at the surface, which have the typical shape shown in Figs. 4(c) and 4(d), propagate in the thickness direction. Figure 2(a) shows that these shear planes penetrate almost to the center of the specimen from both sides. It is also evident from Figs. 2(b) and 2(c) that the plastic deformation originating at the surface propagates through a significant fraction of the specimen thickness [marked by horizontal arrows in 
Figs. 2(b) and 2(c)]. This suggests that the thickness of the specimens used in this study is insufficient to satisfy the plane strain condition for the highly deformable and tough metallic glasses investigated here. However, the specimens in Figs. 2(d) and 2(e) have a relatively small fraction of plane stress fracture surface. For the specimen S7 shown in Fig. 2(d), the distance of the outermost shear band detectable by scanning electron microscopy [defined by the arrow in Fig. 4(c)] was $130 \mu \mathrm{m}$, and the penetration depth of a surface shear band into the thickness direction [measured in Fig. 2(d)] was about $160 \mu \mathrm{m}$. It is thus plausible that the bulk of the sample is far from the influence of surface shear bands; that is, the bulk of the sample could be under plane strain condition and the jagged pattern could be created by shear bands that originate within the sample, not at the surface.

One of the ASTM size requirements for fracture toughness specimen is given by Eq. (1), which implies that the size of the plastic zone must be less than $2 \%$ of the specimen dimensions to obtain a size-independent critical $K_{\text {IC }}$ value. ${ }^{33}$

$$
B, a,(W-a) \geq 2.5 \cdot\left(K_{\mathrm{Q}} \sigma_{\mathrm{y}}\right)^{2} .
$$

From Eq. (1), the critical dimension for the specimen $\mathrm{S} 7$ with $K_{\mathrm{Q}}=54.6 \mathrm{MPa} \cdot \mathrm{m}^{1 / 2}$ and $\sigma_{\mathrm{y}}=1.86 \mathrm{GPa}$ is $2.15 \mathrm{~mm}$, while the actual sample dimensions are $B=2.21 \mathrm{~mm}$, $a=3.96 \mathrm{~mm}$, and $b_{0}=4.04 \mathrm{~mm}$ (initial ligament size, $b_{0}=W-a$ ). Thus, the measured $K_{\mathrm{Q}}$ value for this sample can be regarded as $K_{\mathrm{IC}}$ based on the specimen geometry. Other specimens listed below this sample in Table I (S8-S15) satisfy the size requirement as well.

\section{F. Size of the rough zone and its relationship with measured fracture toughness}

It is worth noting however that the size of the rough zone of specimen S7 measured from the image of Fig. 2(d) [defined as " $L_{\mathrm{A}}$ " in Fig. 2(a)] is $1.43 \mathrm{~mm}$, which is $35 \%$ of the initial ligament size $b_{o}$. In Fig. 7(a), the rough zone region $\left(L_{\mathrm{A}}\right)$ acquired from the fracture surface of each sample is plotted against the plastic zone size, $d$, calculated from the measured $K_{\mathrm{Q}}$ and $\sigma_{\mathrm{y}}$ using Eq. (2) below. ${ }^{3}$

$$
d=\frac{K_{\mathrm{Q}}^{2}}{\pi \sigma_{\mathrm{y}}^{2}} .
$$

As seen from the plot in Fig. 7, the length of the rough zone region observed in the sample fracture surface correlates well with the plastic zone size estimated from the measured $K_{\mathrm{Q}}$ and $\sigma_{\mathrm{y}}$, which suggests that the extent of the jagged pattern propagation is in essence a direct measure of the material fracture toughness. This is borne out in Fig. 7(b), which shows the predicted parabolic
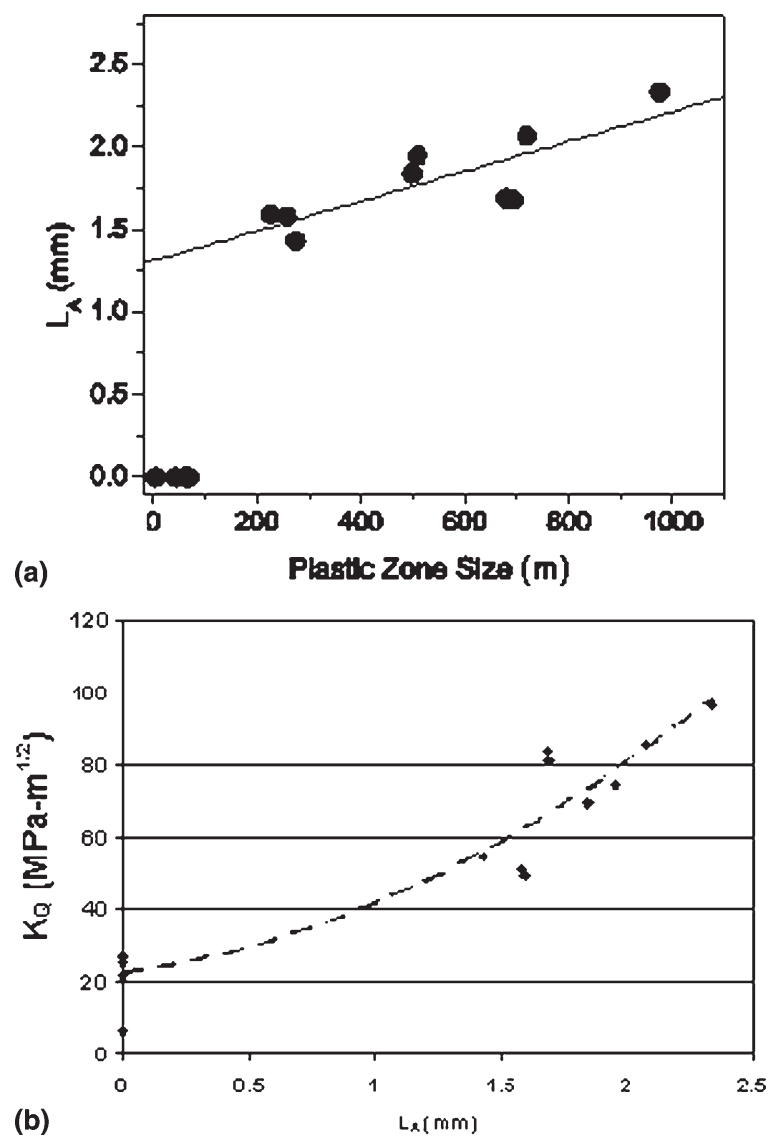

FIG. 7. Correlation between jagged pattern extension [denoted as $L_{\mathrm{A}}$ in Fig. 2(a)] and (a) process zone size calculated from Eq. $(2)^{3}$ and (b) measured fracture toughness.

relationship between fracture toughness, $K_{\mathrm{Q}}$, and rough zone $L_{\mathrm{A}}$.

\section{CONCLUSION}

In summary, in this study, the development of a significant "rough zone" region during fracture of BMG samples that screens a crack tip was confirmed. The development of this jagged rough zone region qualitatively and quantitatively explains why BMGs exhibit good toughness despite a near-zero ductility. Fracture surfaces were revealed showing that the roughness and the length of the jagged region adjacent to the precrack correlates well with the plastic zone size estimated from the measured fracture toughness values. The propagation of these jagged patterns, the main source of energy dissipation in the sample, was attributed to the ability of shear bands to form and propagate far from the surfaces where plane strain conditions prevail. By recognizing that the jagged pattern is primarily the result of shear banding, it is understood that fracture toughness is closely related to the ability of the BMG to undergo a certain amount of plasticity prior to failing by catastrophic fracture. 


\section{ACKNOWLEDGMENTS}

The authors would like to thank Prof. G. Ravichandran of GALCIT, Caltech for providing the MTS test system. This work was supported in part by the MRSEC Program of the National Science Foundation under Award No. DMR-0520565.

\section{REFERENCES}

1. R.D. Conner, W.L. Johnson, N.E. Paton, and W.D. Nix: Shear bands and cracking of metallic glass plates in bending. J. Appl. Phys. 94(2), 904 (2003).

2. R.D. Conner, Y. Li, W.D. Nix, and W.D. Johnson: Shear band spacing under bending of Zr-based metallic glass plates. Acta Mater. 52, 2429 (2004).

3. M.F. Ashby and A.L. Greer: Metallic glasses as structural materials. Scr. Mater. 54, 321 (2006).

4. A. Peker and W.L. Johnson: A highly processable metallic-glass $\mathrm{Zr}_{41.2} \mathrm{Ti}_{13.8} \mathrm{Cu}_{12.5} \mathrm{Ni}_{10} \mathrm{Be}_{22.5}$. Appl. Phys. Lett. 63, 2342 (1993).

5. P. Lowhaphandu and J.J. Lewandowski: Fracture toughness and notched toughness of bulk amorphous alloy: $\mathrm{Zr}-\mathrm{Ti}-\mathrm{Ni}-\mathrm{Cu}-\mathrm{Be}$. Scr. Mater. 38, 1811 (1998).

6. C.J. Gilbert, V. Schroeder, and R.O. Ritchie: Mechanisms for fracture and fatigue-crack propagation in a bulk metallic glass. Metall. Mater. Trans. A 30, 1739 (1999).

7. D. Suh and R.H. Dauskardt: Effects of open-volume regions on relaxation time-scales and fracture behavior of a $\mathrm{Zr}-\mathrm{Ti}-\mathrm{Ni}-\mathrm{Cu}-$ Be bulk metallic glass. J. Non-Cryst. Solids 317, 181 (2003).

8. D. Suh and R.H. Dauskardt: Flow and fracture in Zr-based bulk metallic glasses. Ann. Chim. Sci. Mat. 27, 25 (2002).

9. R.D. Conner, A.J. Rosakis, W.L. Johnson, and D.M. Owen: Fracture toughness determination for a beryllium-bearing bulk metallic glass. Scr. Mater. 37, 1373 (1997).

10. K.M. Flores and R.H. Dauskardt: Enhanced toughness due to stable crack tip damage zones in bulk metallic glasses. Scr. Mater. 41, 937 (1999).

11. W.L. Johnson: Bulk glass-forming metallic alloys: Science and technology. MRS Bull. 24(10) 42 (1999).

12. P. Tandaiya, R. Narasimhan, and U. Ramamurty: Mode I crack tip fields in amorphous materials with application to metallic glasses. Acta Mater. 55, 6541 (2007).

13. C.P. Kim, J.Y. Suh, A. Wiest, M.L. Lind, R.D. Conner, and W.L. Johnson: Fracture toughness study of new Zr-based Be-bearing bulk metallic glasses. Scr. Mater. 60, 80 (2009).

14. X.K. Xi, D.Q. Zhao, M.X. Pan, W.H. Wang, Y. Wu, and J.J. Lewandowski: Fracture of brittle metallic glasses: Brittleness or plasticity. Phys. Rev. Lett. 94, 125510 (2005).

15. J.J. Lewandowski, W.H. Wang, and A.L. Greer: Intrinsic plasticity or brittleness of metallic glass. Philos. Mag. Lett. 85. 77 (2005).
16. C.J. Gilbert, R.O. Ritchie, and W.L. Johnson: Fracture toughness and fatigue-crack propagation in a $\mathrm{Zr}-\mathrm{Ti}-\mathrm{Ni}-\mathrm{Cu}-\mathrm{Be}$ bulk metallic glass. Appl. Phys. Lett. 71, 476 (1997).

17. A. Tatschl, C.J. Gilbert, V. Schroeder, R. Pippan, and R.O. Ritchie: Stereophotogrammetric investigation of overload and cyclic fatigue fracture surface morphologies in a $\mathrm{Zr}-\mathrm{Ti}-\mathrm{Ni}-$ Cu-Be bulk metallic glass. J. Mater. Res. 15, 898 (2000).

18. C.A. Schuh, T.C. Hufnagel, and U. Ramamurty: Overview No. 144 -Mechanical behavior of amorphous alloys. Acta Mater. 55. 4067 (2007).

19. A.S. Argon and M. Salama: Mechanism of fracture in glassy materials capable of some inelastic deformation. Mater. Sci. Eng. 23, 219 (1976).

20. G.T. Hahn and A.R. Rosenfield: Local yielding and extension of a crack under plane stress. Acta Metall. 13, 293 (1965).

21. J.H. Schneibel, J.A. Horton, and P.R. Munroe: Fracture toughness, fracture morphology and crack-tip plastic zone of a $\mathrm{Zr}$ based bulk amorphous alloy. Metall. Mater. Trans. A 32, 2819 (2001).

22. F. Spaepen and D. Turnbull: Mechanism for flow and fracture of metallic glasses. Scr. Metall. 8, 563 (1974).

23. H.J. Leamy, H.S. Chen, and T.T. Wang: Plastic-flow and fracture of metallic glass. Metall. Trans. 3, 699 (1972).

24. A.T. Alpas, L. Edwards, and C.N. Reid: Fracture and fatiguecrack propagation in a nickel-base metallic-glass. Metall. Trans. A 20. 1395 (1989).

25. Z.F. Zhang, J. Eckert, and L. Schultz: Difference in compressive and tensile fracture mechanisms of $\mathrm{Zr}_{59} \mathrm{Cu}_{20} \mathrm{Al}_{10} \mathrm{Ni}_{8} \mathrm{Ti}_{3}$ bulk metallic glass. Acta Mater. 51, 1167 (2003).

26. L.A. Davis: Fracture toughnesses of metallic glasses. Metall. Trans. A 10, 235 (1979).

27. P. Lowhaphandu, L.A. Ludrosky, S.L. Montgomery, and J.J. Lewandowski: Deformation and fracture toughness of a bulk amorphous $\mathrm{Zr}-\mathrm{Ti}-\mathrm{Ni}-\mathrm{Cu}-\mathrm{Be}$ alloy. Intermetallics 8, 487 (2000).

28. N. Nagendra, U. Ramamurty, T.T. Goh, and Y. Li: Effect of crystallinity on the impact toughness of a La-based bulk metallic glass. Acta Mater. 48, 2603 (2000).

29. C.J. Gilbert, J.M. Lippmann, and R.O. Ritchie: Fatigue of a $\mathrm{Zr}-\mathrm{Ti}-\mathrm{Cu}-\mathrm{Ni}-\mathrm{Be}$ bulk amorphous metal: Stress/life and crackgrowth behavior. Scr. Mater. 38, 537 (1998).

30. P.A. Hess and R.H. Dauskardt: Mechanisms of elevated temperature fatigue crack growth in $\mathrm{Zr}-\mathrm{Ti}-\mathrm{Cu}-\mathrm{Ni}-\mathrm{Be}$ bulk metallic glass. Acta Mater. 52, 3525 (2004).

31. H. Gao: 3-dimensional slightly nonplanar cracks. J. Appl. Mech. 59. 335 (1992).

32. B. Cotterell and J.R. Rice: Slightly curved or kinked cracks. Int. J. Fract. 16, 155 (1980).

33. T.L. Anderson: Fracture Toughness Testing of Metals, Fracture Mechanics: Fundamentals and Applications, 1st ed. (CRC Press, Boca Raton, FL, 1991), p. 431. 